\title{
MÁS ALLÁ DE LAS NUEVAS POBLACIONES DE ANDALUCÍA. LA ESTRATEGIA DE ASCENSO DE FREY FERNANDO DE QUINTANILLA EN LA ORDEN MILITAR DE SAN JUAN
}

\author{
Adolfo Hamer-Flores \\ Universidad Loyola Andalucía
}

\begin{abstract}
Resumen. En 1767, Carlos III encomendó a Pablo de Olavide la puesta en marcha y la administración de las Nuevas Poblaciones que se establecieron en territorios segregados de la provincia de La Mancha y de los reinos de Jaén, Córdoba y Sevilla. La envergadura del proyecto hizo que Olavide nombrase, en 1768, a Fernando de Quintanilla como subdelegado de las Nuevas Poblaciones de Andalucía. Muy pronto, las ideas ilustradas del primero influyeron notablemente en el segundo, que las adoptó y defendió hasta 1776. No obstante, la detención y posterior condena inquisitorial del superintendente le harían renunciar a esas ideas y suplicar repetidamente poder retirarse a su localidad natal. El gobierno rechazó durante años sus peticiones, pero, mientras tanto, Quintanilla se centró en mejorar su posición dentro de la orden de San Juan; con tanto éxito que en sus dos últimas décadas de vida disfrutó de varias encomiendas y bailiajes que, además, le permitieron disponer de unos ingresos muy considerables.
\end{abstract}

Palabras clave: Fernando de Quintanilla, Orden de Malta, Nuevas Poblaciones de Andalucía, siglo XVIII.

ABSTRaCT. In 1767, Carlos III entrusted Pablo de Olavide with the creation and administration of the New Settlements that were established in segregated territories of the province of La Mancha and the kingdoms of Jaen, Cordova and Seville. The scope of the project caused Olavide to appoint Fernando de Quintanilla in 1768 as a sub-delegate of the New Settlements of Andalusia. Very soon, the Enlightenment ideas of the first greatly influenced the second, who adopted and defended them until 1776. However, the arrest and subsequent inquisitorial sentence of the superintendent would make him renounce those ideas and repeatedly beg to

Recibido: 18-11-2019 - Aceptado: 26-2-2020 • adolfo.hamer@gmail.com 
be able to retire to his hometown. The government rejected their requests for years, but, in the meantime, Quintanilla focused on improving its position within the San Juan order; with such success that in his last two decades of life he enjoyed several encomiendas and bailiajes that, in addition, allowed him to enjoy a considerable income.

Keywords: Fernando de Quintanilla, Order of Malta, New Settlements of Andalusia, $18^{\text {th }}$ century.

EL MES DE NOviEMBRE DE 1776 supuso un verdadero punto de inflexión en la corta historia de las Nuevas Poblaciones de Sierra Morena y Andalucía. Después de numerosas delaciones, el Santo Tribunal de la Inquisición procedió a detener y encarcelar en Madrid a Pablo de Olavide, superintendente de dichas poblaciones y asistente de la ciudad de Sevilla, el cual fue retenido en las cárceles secretas del Santo Oficio hasta el «autillo de fe» condenatorio de 24 de noviembre de 1778 (Defourneaux, 1965; Perdices de Blas, 1992). Como era de esperar, la mayor parte de las ideas e iniciativas del limeño se interrumpieron casi de inmediato, incluso en las nuevas colonias se temió que se abandonase o reformulase profundamente este proyecto por la caída de su principal impulsor. El gobierno apostó por una continuidad de mínimos ${ }^{1}$, tanto que incluso dejó pasar casi una década sin proveer la vacante en la Superintendencia, que fue desempeñada interinamente por el subdelegado de las Nuevas Poblaciones de Sierra Morena ante la forzosa necesidad de adoptar algunas decisiones. Hubo que esperar hasta 1784 para que se produjera una modificación en el sistema de gobierno al transformar esa Superintendencia en una Intendencia y, en consecuencia, proceder al nombramiento de un intendente; empleo que recayó en el que hasta entonces había sido subdelegado en La Carolina (Hamer Flores, 2009, pp. 7-10).

Mientras tanto, en las Nuevas Poblaciones de Andalucía² un individuo que gozó de la máxima confianza de Olavide debió continuar ejerciendo el empleo de subdelega-

Una de las cuestiones en la que se siguió apostando decididamente en las nuevas colonias fue la de fomentar el trabajo y rechazar la vagancia. La Corona no estaba dispuesta a permitir que un proyecto que había promovido directamente, y del cual estaban pendientes el resto de los gobiernos europeos, con el objetivo de incrementar la riqueza del reino se viera afectado por aquello que en el siglo de las Luces se combatía. Al igual que los restantes vasallos, los colonos debían ser individuos útiles y tanto sus acciones como sus castigos buscar alguna utilidad (véase, al respecto, Rodríguez Ennes, 2018). Un análisis reciente y actualizado que evalúa el crecimiento económico español en el siglo XVIII puede encontrarse en Llopis y Sebastián, 2019.

2 Las Nuevas Poblaciones de Sierra Morena y Andalucía se dividían en dos partidos territoriales que, aunque integraban una única jurisdicción, se gestionaron con una enorme autonomía: en cada uno de ellos existían una contaduría y un alcalde mayor con jurisdicción solo sobre ese partido. El partido territorial de las Nuevas Poblaciones de Sierra Morena, con capital en La Carolina, se conformó con tierras segregadas al reino de Jaén y a la provincia de La Mancha; y el mencionado partido de 
do, paradójicamente, por la oposición del gobierno a autorizar sus reiteradas peticiones de retiro. Realidad que tampoco impidió que sus aspiraciones de promocionar en ellas se diluyeran por completo al considerar dicho gobierno que la buena marcha de las colonias era una obligación del cargo y no un mérito con el que conseguir recompensas; buena prueba de ello fue la negativa de Madrid a concederle un aumento de sueldo en 1778 y los honores y sueldo de intendente de ejército que solicitó en octubre de 1782 en recompensa de sus años en las nuevas poblaciones ${ }^{3}$. No puede extrañar, por tanto, que algunas de las decisiones de gobierno que adoptó Fernando de Quintanilla después de la detención del superintendente muestren un evidente desencanto con el proyecto colonizador o que desde ese momento pusiese sus miras en promocionar dentro de la Orden de San Juan de Jerusalén, de la que era miembro profeso. Esta compleja etapa ha sido objeto de algunas investigaciones, no así su apuesta por centrarse en la Orden Hierosolimitana, que es prácticamente desconocida en la historiografía, a pesar de la destacada posición que llegó a detentar en ella en sus últimos años de vida (Aguayo Pérez y Hamer Flores, 2007). Es por ello por lo que esta investigación se propone como objetivo principal el conocer los cargos y dignidades que Quintanilla tuvo en la referida orden militar y cómo ello repercutió en su patrimonio, con lo cual podremos tener una visión más completa de la trayectoria personal de uno de los gobernantes más destacados de las Nuevas Poblaciones impulsadas por Carlos III a partir de 1767.

El estudio de estos aspectos nos permitirá, además, acercarnos mejor a la que podemos considerar como estrategia de supervivencia social de quien compartió hasta tal punto las ideas y proyectos ilustrados de Pablo de Olavide que este último propuso al gobierno, en 1771, que lo nombrase intendente de todas las Nuevas Poblaciones bajo su autoridad para así poder centrarse en los asuntos de la Asistencia de Sevilla ${ }^{4}$. El rey no tuvo a bien conferirle este cargo, pero sí le concedió en mayo del año siguiente el grado de intendente de provincia ${ }^{5}$ y el sueldo anual de 30.000 reales, que se sumaron

las Nuevas Poblaciones de Andalucía, con capital en La Carlota, estuvo integrado por territorios que antes habían pertenecido a los reinos de Córdoba y de Sevilla.

Archivo General de Simancas (en adelante A.G.S.), Secretaría y Superintendencia de Hacienda, leg. 499, docs. 551 y 552. Carta de Fernando de Quintanilla a Miguel de Múzquiz, 10 de octubre de 1782.

$4 \quad$ Olavide lo solicita de este modo a Miguel de Múzquiz, secretario de Estado y del Despacho de Hacienda, el 25 de agosto de 1771: «Me es pues necesario mantener un sujeto de confianza en las poblaciones de Andalucía, y ninguno puede ser más a propósito que Quintanilla, que las ha criado (sic) ejecutando mis órdenes con admirable exactitud y diligencia. Pero para esto es menester que después de haber hecho un mérito tan distinguido, y para que pueda animarse en continuarlo, $\mathrm{Su}$ Majestad se sirva de condecorarlo de algún modo, bien sea con el grado de Intendente que yo le propuse, y que en nada se opone a la Superintendencia, que yo conservo, o con el que fuere de su superior dignación» (Perdices de Blas, 1988, 3, p. 1344).

5 Según se publicó en ese mismo año, Fernando de Quintanilla, caballero del orden de San Juan, recibió honores y grado de intendente de provincia «en atención a sus distinguidas circunstancias y 
a un margen de autonomía muy considerable en la dirección de su partido territorial ${ }^{6}$. Aun así, todo ello pasó a un segundo plano, como decíamos, a partir de 1776, cuando la necesidad de renunciar al modelo ilustrado que impulsó Olavide hizo que se volcase nuevamente en las prácticas de promoción social y económica vigentes en su época.

\section{Fernando de Quintanilla, subdelegado de Pablo de Olavide en las Nuevas Poblaciones de Andalucía}

La familia Quintanilla era una de las más destacadas entre las oligarquías de la ciudad de Carmona y de la villa de Lora del Río, ambas en el reino de Sevilla, por lo que no es extrañar que Pablo de Olavide, como asistente de su capital desde 1767, los conociera o al menos tuviera referencias de ellos desde muy pronto. De hecho, cuando el limeño aún no había recibido contestación del Consejo de Castilla a su propuesta de instalar nuevas poblaciones en La Parrilla no duda en estudiar otras posibles zonas de colonización; entre ellas, un espacio situado al noreste de Sevilla, alrededor de Constantina, Villanueva y Lora del Río. Como fruto de este amago, que parece que no se gestionó con demasiada discreción, recibió la solicitud de siete familias de Lora que le pedían la concesión de cincuenta fanegas de tierra a cada una de ellas en el lugar conocido como Lentiscal del Membrillo (Defourneaux, 1965, p. 440). El superintendente, para evacuar las informaciones necesarias en este asunto, acudió a Fernando de Quintanilla, «caballero de la orden de San Juan, vecino de la misma villa y sujeto de conocida integridad e inteligencia, para que [le] expresase las calidades de los pretendientes $\rangle^{7}$ (Perdices de Blas, 1992, p. 265). Petición a la que respondió con rapidez y mostrando grandes conocimientos en la materia.

Sin ni siquiera conocerlo, Olavide ya se había formado un buen concepto sobre Quintanilla; impresión que mejoró aún más tras entrevistarse personalmente con él. Lo vio entonces dotado de un gran talento ${ }^{8}$, por lo que decidió encargarle que se ocu-

al celo y desinterés con que ha servido y desempeña la subdelegación de las Nuevas Poblaciones a cargo de don Pablo de Olavide» (Mercurio Histórico y Politico que contiene el estado presente de la Europa, lo sucedido en todas las cortes, los intereses de los príncipes y generalmente todo lo más curioso, perteneciente al mes de julio de 1772, Madrid, Imprenta Real de la Gazeta, 1772, pp. 374-375).

6 Archivo Histórico Nacional (en adelante A.H.N.), Fondos Contemporáneos, Gobernación, leg. 279, exp. 6. Carta de Fernando de Quintanilla a Miguel de Múzquiz, 8 de julio de 1778.

7 En estos términos se expresa Olavide en una carta dirigida al Consejo de Castilla y fechada en Sevilla el 8 de marzo de 1768 .

8 Sobre este hecho son muy reveladoras las palabras que Olavide dirige a Múzquiz el 22 de marzo de 1769: «[Fernando de Quintanilla] es procurador general del orden de San Juan, uno de los sujetos de la primera distinción de este país y uno de los más ricos hacendados. La buena fama que corría de este sujeto me hizo buscar la ocasión de tratarle y hallé en él un talento muy superior al común, una probidad y rectitud de ideas no vulgar. Tanto que hice concepto de que sería muy a propósito 
para de la recepción de colonos y organización inicial de las Nuevas Poblaciones de Andalucía 9 . En un primer momento, el loreño fue reticente a cambiar su vida tranquila y retirada por otra dura y trabajadora, pero finalmente accedió. Sabemos que llegó a estas colonias el 9 de mayo de $1768^{10}$, pasando a establecerse durante algunos meses en la única construcción existente entonces en ellas: la hacienda de los regulares expulsos de San Sebastián de los Ballesteros ${ }^{11}$. Llegaba solo como comisionado de Olavide para dirigir los trabajos iniciales, pero el frustrado nombramiento de Luis de Urbina, marido de su prima Gracia Estefanía de Olavide, como subdelegado de esas colonias facilitó que el 15 de julio decidiera concederle este nombramiento, el cual fue confirmado por el rey unos días más tarde. Se situó a partir de ese momento al frente de uno de los dos partidos territoriales de esta nueva jurisdicción, gobernando desde su capital, La Carlota, a los colonos establecidos en esta y en las colonias de Fuente Palmera, La Luisiana y San Sebastián de los Ballesteros.

Su labor fue verdaderamente ingente, pues mientras que Miguel de Jijón, subdelegado de las Nuevas Poblaciones de Sierra Morena, contó muy frecuentemente con la ayuda de Olavide para el establecimiento de esas nuevas colonias, nuestro biografiado debió hacerlo casi todo él; ya que las visitas del superintendente a La Carlota fueron escasas y casi siempre muy breves (Aguayo Pérez y Hamer Flores, 2007, pp. 274-275). Algo que no impidió que la personalidad y el modo de pensar del limeño tuvieran un impacto muy considerable en nuestro personaje. La historiografía, sin duda muy influenciada por las opiniones vertidas en 1833 por Pedro Polo de Alcocer ${ }^{12}$, generalmente muy críticas con todos sus predecesores, ha venido considerando al primer subdelegado de las colonias de Andalucía como un personaje de escasa relevancia; hasta el punto de haber sido tildado de insignificante (Caro Baroja, 1952, p. 56). No obstante, un análisis menos superficial nos demuestra que tal vez nos encontramos ante uno de los más fieles seguidores de las ideas y proyectos de Olavide, hasta el

para ponerlo a la cabeza de las nuevas poblaciones que me mandaba el rey hacer en Andalucía» (Perdices de Blas, 1992, p. 265).

$9 \quad$ Aunque el padre de Fernando de Quintanilla había nacido en el virreinato del Perú, no nos consta ninguna referencia a posibles contactos entre los Quintanilla y la familia de Olavide en el continente americano. Es probable que esto se deba al traslado del primero a Europa dos décadas antes de que naciera Pablo de Olavide en 1725. De este modo, no solo los personajes que estudiamos no se conocían previamente, sino que además tampoco manifiestan en su correspondencia vínculos a través de parientes o conocidos.

10 A.H.N., Fondos Contemporáneos, Gobernación, leg. 279, exp. 6. Carta de Fernando de Quintanilla a Miguel de Múzquiz, 8 de julio de 1778 .

11 A.H.N., Inquisición, leg. 3607, s.f. Carta de Fernando de Quintanilla a Pablo de Olavide, 15 de mayo de 1768 .

12 A.H.N., Fondos Contemporáneos, Gobernación, leg. 2738, exp. 16. 
punto de haberse modificado sustancialmente la profunda religiosidad de la que había hecho gala durante toda su vida.

A modo de ejemplo, expondremos a continuación un par de casos que ejemplifican bien lo que acabamos de manifestar. Después de cuatro años al frente de las nuevas colonias, tan volcado en ellas que no regresó durante este tiempo a su localidad natal, en junio de 1772 decidió pasar unos días en Lora del Río y asistir así a los festejos de acción de gracias a María Santísima de Setefilla, de cuya cofradía era mayordomo, para que cesasen las lluvias y no se dañasen las cosechas (Montalbo, 1960 y Lozano Nieto, 1986). Sin embargo, a su llegada, todo lo que antes de su partida había visto bien en este tipo de eventos ahora le escandalizaba. El Fernando de Quintanilla que hasta 1768 hacía que todos sus criados rezaran el Rosario junto a él, ahora se quejaba abiertamente por el exceso de gasto, considerando suficientes solo dieciocho luces en el altar, y por tantas funciones a los santos y a la Virgen, pues se debía dirigir todo preferentemente a Dios. Incluso responsabilizaba de estas prácticas a tanto cura y fraile poco instruidos en la religión, causando tal escándalo entre los oyentes que su hermana Ana María, casada con Alonso Montalvo, le dijo: «Anda Fernando, que tú vienes tan hereje como Olavide». Los dos sermones que pronunció al día siguiente el padre Manuel Gil encontraron, en cambio, una cálida acogida entre los vecinos, especialmente porque, a pesar de no haber tenido noticia de las afirmaciones de Quintanilla, demostraban la utilidad de este tipo de devociones y desacreditaban lo que aquel les había dicho en la noche anterior. Paradójicamente, la mala acogida que tuvieron sus afirmaciones no hizo que nuestro personaje adoptara una postura más conciliadora pues, al parecer, hubo que hacer un gran esfuerzo para que autorizase otra función religiosa el martes siguiente en la que pudiera haber más de dieciocho luces, ya que como apoderado del bailío de Lora ${ }^{13}$ tenía autoridad para impedirlo. De todos modos, al ver en esta celebración un gran número de frailes no dudó en mostrar nuevamente su indignación por ello ${ }^{14}$.

Otro ejemplo de su sintonía con el superintendente lo encontramos en el gran celo que mostró porque se cumplieran en las colonias situadas bajo su jurisdicción las disposiciones de Olavide relacionadas con la forma de vestir de las mujeres. El limeño se oponía frontalmente al modo tradicional en el que estas se vestían para salir a la calle y, sobre todo, para asistir a la iglesia. Esa profusión de mantillas, pañuelos

13 Fernando de Quintanilla fue apoderado, durante muchos años, de dos bailíos de Lora. En primer lugar, a partir de 1767 lo fue de Pedro Messía de la Cerda, caballero profeso de la Orden de Malta, quinto marqués de Guadalcázar, teniente general de la Real Armada y virrey de Nueva Granada, que fallecería en Madrid en 1783. En segundo lugar, también actuó como apoderado del nuevo bailío Francisco González de Avellaneda, señor de Benavente.

14 A.H.N., Inquisición, leg. 1866, pieza 1, testigo 30 (Manuel Gil, 1773). 
y demás prendas con las que se cubrían hasta casi no dejar parte del cuerpo visible le parecía una costumbre atrasada y su mantenimiento lo relacionaba con la influencia que ejercía el clero sobre ellas; de ahí que hiciera todo lo posible para que dejasen de usar esas prendas. Así pues, en las nuevas colonias las mujeres podían y debían ir con la cabeza y cuello descubiertos tanto por la calle como a los oficios religiosos; iniciativa que, claro está, nunca contó con la aprobación del sector eclesiástico ${ }^{15}$.

Finalmente, este ambiente ilustrado en el que se sumergió por completo gracias a la colonización facilitaría la participación de nuestro personaje en la Real Sociedad Patriótica de Sevilla, puesta en marcha en 1775 después de varias reuniones en el alcázar sevillano bajo la supervisión de Olavide. El 24 de marzo el concejo hispalense acordó su formación designando los cuarenta socios de número que la constituirían, procediéndose al acto de fundación oficial el 15 de abril en el alcázar estando también presente el asistente; que recibió el honor de ser presidente de esta Sociedad, posteriormente conocida como Real Sociedad Económica de Amigos del País de Sevilla, mientras desempeñase ese cargo por su contribución a su puesta en marcha (Calderón España, 1993, pp. 51-71). En el ejemplar impreso en 1778 de los estatutos aprobados definitivamente en diciembre del año anterior por el Consejo de Castilla consta Fernando de Quintanilla como socio correspondiente en La Carlota ${ }^{16}$, situación que cambió a partir de 1785, cuando debido a su jubilación empezó a aparecer como correspondiente en Lora ${ }^{17}$. Del mismo modo, sus hermanos Luis y Bartolomé de Quintanilla, al igual que su sobrino Juan Rodrigo de Quintanilla y Arze, también recibieron el nombramiento de socios correspondientes en la ciudad de Carmona ${ }^{18}$. En el caso concreto de Bartolomé, destacó gracias a sus estudios para la mejora de la agricultura, llegando a elaborar en 1777 una memoria sobre pastos para concurrir a un premio que convocaba la Real Sociedad Económica Matritense de Amigos del País ${ }^{19}$.

No puede sorprendernos, pues, que la detención de Olavide en 1776 y su sentencia condenatoria en el autillo inquisitorial de 1778 implicasen un antes y un después en su labor de gobierno en las nuevas colonias ${ }^{20}$. Justo entonces comenzó a enviar a

\footnotetext{
15 A.H.N., Inquisición, leg. 1866, pieza 3, testigo 147 (José Lázaro Sánchez Rubio, 1777).

16 Estatutos de la Real Sociedad Patriótica de la M.N. y M.L. ciudad de Sevilla y su reinado, Sevilla, Imprenta de don Manuel Nicolás Vázquez y compañía, 1778, p. 76.

17 Señores socios de la Real Sociedad Patriótica de la ciudad y reino de Sevilla, existentes en el año de mil setecientos ochenta y cinco, [Sevilla, 1785], s/p.

18 Continuación de las memorias de la Real Sociedad Patriótica. $N^{o} 2$, Sevilla, Impresores de la Real Sociedad, 1779, p. 597.

19 Memorias de la Sociedad Económica. Tomo tercero, Madrid: Por don Antonio de Sancha, 1787, p. 65. Véase también Antón Ramírez, 1865, p. 916.

20 Esta circunstancia se puede observar incluso en el hecho de que en los años siguientes llegó incluso a solicitar para sí mismo unas tierras vacantes de buena calidad que debería haber asignado a familias labradoras en las nuevas poblaciones (Hamer Flores, 2007). Asistimos, pues, a un cambio tan radical
} 
Madrid peticiones en las que solicitaba poder jubilarse conservando el salario y grado de intendente o, en su defecto, la autorización para gobernarlas desde su localidad natal. Su quebrantada salud, según manifestaba al ministro de Hacienda, le impedía seguir más tiempo en La Carlota al frente de ellas. El gobierno, sin embargo, no consideró que este fuera el mejor momento para dejar vacante un cargo tan significativo, por lo que el rey no accedió a la petición de retiro, pero sí le autorizó a que pudiera pasar tres meses al año en la casa de campo que tenía en Lora del Río². Las solicitudes no se interrumpieron en los años siguientes, recibiendo siempre respuestas en términos similares. Solo cuando en 1784 se consideró factible transformar las nuevas colonias en una Intendencia, nombrando intendente al que hasta entonces había sido subdelegado de las Nuevas Poblaciones de Sierra Morena, nuestro personaje logró su ansiada jubilación ${ }^{22} \mathrm{y}$, por consiguiente, pudo trasladar su residencia permanentemente a su localidad natal ${ }^{23}$. Esta villa contaba por aquel entonces con unos 4.609 habitantes, de los que solo 24 tenían la consideración de hidalgos ${ }^{24}$, lo que implicaba de facto que no sería muy difícil gozar de una importante posición en un contexto en el que la nobleza y las oligarquías eran muy escasas.

\section{Frey Fernando de Quintanilla y la Orden de San Juan de Jerusalén}

Fernando de Quintanilla, como ya hemos indicado, vio la luz en la villa sevillana de Lora del Río el 9 de septiembre de 1719 en el seno de una familia hidalga oriunda de la vecina ciudad de Carmona, pero asentada en esta localidad desde comienzos del siglo XVII. Sus padres fueron Juan Rodrigo de Quintanilla y Andrade, natural de Cajamarca en Perú, donde nació en 1673, y María Manuela de Quintanilla y Briones, nacida en Lora en $1679^{25}$. Un matrimonio que tendría, al menos, catorce hijos tras

que lo llevó de trabajar durante años sin recibir ningún tipo de salario a procurar fundamentalmente un beneficio personal incluso en un proyecto cuyos objetivos había compartido inicialmente. En este sentido, no es extraño que también procurase el mayor beneficio económico y social dentro de la Orden de San Juan en esos mismos años.

21 A.H.N., Fondos Contemporáneos, Gobernación, leg. 279, exp. 6. Carta de Fernando de Quintanilla a Miguel de Múzquiz, 8 de julio de 1778. La decisión de Carlos III se le comunica con fecha de 30 de julio.

22 La solicitud de jubilación que, finalmente, obtuvo el plácet fue remitida en enero de 1784 (A.H.N., Fondos Contemporáneos, Gobernación, leg. 279, exp. 6).

23 Allí viviría, en compañía de su sobrina María Manuela de Quintanilla, en el palacio que se había mandado construir en la Roda de Enmedio (Archivo Municipal de Lora del Río (en adelante A.M.L.), Secretaría General, Padrones y censos, leg. 109. Padrones municipales de 1796 y 1798).

$24 \quad$ Censo de Floridablanca 1787. Comunidades Autónomas Meridionales, Madrid, INE, 1987, pp. 78 y 106.

25 Lista de los caballeros del M. Yll. Priorado de Castilla y León, [S.1.], [s.n.], 1795, pp. 6-7. Una transcripción de su acta de bautismo en A.H.N., Órdenes Militares, San Juan de Jerusalén, exp. 23543: 
contraer nupcias en mayo de 1704: Antonio, Bartolomé, Ana, Leonor, Rodrigo, María Manuela, Isabel, Rodrigo, Fernando, Luis, Francisco, Juan José, Luis Cayetano y Ana de Quintanilla (González Carballo, 2018, pp. 119-133). Nuestro personaje, por tanto, fue el noveno hijo de un destacado miembro de la oligarquía local que desempeñaría el cargo de alcalde ordinario por el estado noble hasta en seis ocasiones - 1705, 1706, 1710, 1716, 1721 y 1722 — y el de alcalde de la Santa Hermandad en otra — 1723 — ${ }^{26}$, a lo que debemos añadir el importante papel que también tuvo como mayordomo de la cofradía de Nuestra Señora de Setefilla hasta su fallecimiento, acaecido en 1727; siendo sucedido en el cargo por su hijo mayor Antonio de Quintanilla hasta 1767, fecha en la que tuvo lugar la aprobación de unas nuevas constituciones para la cofradía (Lozano Nieto, 1986, p. 97).

Pero por si todo ello no fuera suficiente, de la relevancia social de esta familia también daba cumplida cuenta la presencia de su escudo de armas tanto en la capilla de San Bartolomé de la iglesia parroquial de Santa María de la Asunción como en el convento franciscano de San Antonio de Lora, en el que eran patronos ${ }^{27}$. A los que el propio Fernando de Quintanilla sumó otro más que ubicó en la fachada del palacio que mandó construir, a partir de 1781, en la calle Roda de Enmedio para pasar los últimos años de su vida (Lozano Nieto, 1986, p. 94). Una construcción en la que la influencia de las Nuevas Poblaciones es innegable, pues su parecido con el palacio de la Subdelegación de La Carlota, construido bajo sus órdenes unos años antes, era y es muy evidente.

Al nacer y vivir en la cabecera del bailiaje más importante de la Orden Hierosolimitana en su Gran Priorato de Castilla y León, las relaciones cercanas e incluso la incorporación a esta de alguno de los hijos de las familias principales se convirtió en algo habitual. La necesidad de demostrar, entre otros, la condición de noble y las posibilidades que se abrían para obtener alguna renta con la que vivir holgadamente,

«En la villa de Lora en once días del mes de septiembre de mil setecientos y diez nueve años yo Juan (sic) fray Juan Pizarro predicador general y guardián del convento del señor san Antonio de esta villa de Lora, de la santa provincia de los Ángeles, con licencia del señor fray don Gregorio Barco, del hábito de San Juan, prior, vicario y visitador, primer ordinario y eclesiástico de esta villa bauticé a Fernando de las Nieves José Joaquín Francisco Antonio Straton, hijo legítimo de Juan Francisco de Quintanilla y Andrade, alcalde mayor perpetuo de la ciudad de Carmona y regidor de esta dicha villa, y de doña María Manuela de Quintanilla. Fueron sus padrinos don Lope Carrillo de Andrade, capitán de caballos corazas y gobernador y capitán general de la provincia de Caracas, su tío, y doña Leonor de Briones Monsalve, su abuela, a los cuales amonesté el parentesco espiritual como lo dispone el Santo Concilio de Trento y lo firmé. Nació a nueve días de dicho mes y año. Fray don Gregorio Barco. Fray Juan Pizarro».

26 A.H.N., Órdenes Militares, San Juan de Jerusalén, exp. 23543.

27 A.H.N., Órdenes Militares, San Juan de Jerusalén, exp. 23543. 
la transformaron en un marcador de estatus y limpieza de sangre ${ }^{28}$ a la vez que un interesante destino para los hijos que no estaban destinados a recibir mayorazgos o muchos bienes en herencia, es decir, los más pequeños. La familia de nuestro personaje, en este sentido, se ajustó a esta costumbre al destinar a tres de los ocho hijos varones que llegaron a adultos para su ingreso en la Orden: Francisco, Fernando y Luis. Además, otro de ellos, Juan José de Quintanilla, se ordenó sacerdote (González Carballo, 2018, p. 132).

\section{a) Vinculación a la Orden de Malta}

La primera vinculación de Fernando de Quintanilla a la Orden de Malta se produjo cuando ni siquiera había cumplido los ocho años. Previa petición de sus progenitores fue recibido como caballero de justicia, con gracia y dispensa de menor de edad, en virtud de un breve de Benedicto XIII de 13 de junio de 1727 y de una bula del gran maestre fechada en 10 de julio de 1727. Unas gestiones por las que se depositaron en manos del embajador de Malta en España un total de 16.734 reales y 4 maravedíes de plata moderna en julio de 1729. El 4 de enero de 1737, cuando contaba ya con edad suficiente para ello, se le formó asiento para servir al rey español en las Reales Guardias Marinas, donde alcanzó el grado de alférez de fragata. En este cuerpo era muy apreciada la formación intelectual y naval de los caballeros sanjuanistas que, además, al no tener familia a su cargo, podían dedicarse plenamente a la vida militar (González Carballo, 2018, p. 137; Castellano Cuesta, 2018, pp. 75-76).

En cuanto alcanzó la edad necesaria, su madre y tutora solicitó a finales de 1739 su admisión y la de su hermano Francisco de Quintanilla como caballeros de justicia en grado de mayores de edad, para lo que se realizaron unas probanzas de nobleza, limpieza de sangre y legitimidad. Estas no se diferenciaban demasiado de las correspondientes a otras órdenes militares españolas y, una vez concluidas, tuvieron el visto bueno de la Asamblea de la orden en mayo de 1741, haciendo posible que ambos hermanos profesasen en ese mismo año ${ }^{29}$. El día de la investidura, el neófito, tras haber confesado, con vestidura larga y suelta se presentaba ante el altar llevando una vela grande encendida en la mano para oír misa y comulgar. Tras ello, comunicaba al delegado del Gran Maestre su deseo de ser recibido en la Orden de San Juan, quien le explicaba sus obligaciones. Aceptadas por el neófito, se procedía a recitar la fórmula de profesión, tras la que pasaba a ser freire y a llevar el hábito. En febrero de 1744

\footnotetext{
28 Obviamente, también se recurrió a otras órdenes militares e instituciones con este mismo objetivo. De ahí que el hermano mayor de Fernando ingresara en 1727 en la Real Maestranza de Sevilla (González Carballo, 2018, p. 119).

29 A.H.N., Órdenes Militares, San Juan de Jerusalén, exp. 23543 (Fernando de Quintanilla) y exp. 23544 (Francisco de Quintanilla).
} 
encontramos a nuestro personaje en Malta prestando sus servicios militares o caravanas con su hermano frey Francisco de Quintanilla y su otro hermano novicio frey Luis de Quintanilla, pues una de las obligaciones de todo miembro profeso en la Orden para que esta profesión tuviera completa validez era haber corrido las caravanas durante tres años en las galeras y navíos de la Orden (González Carballo, 2018, pp. 141-143; Salazar y Acha, 2015, pp. 246-247).

Posteriormente volvió a servir al rey español en su ejército, alcanzando el grado de capitán del regimiento de infantería de España ${ }^{30}$. Ahora bien, problemas de salud le obligaron a dejar la vida militar y decidió entonces regresar definitivamente a Lora ${ }^{31}$. Desconocemos el momento exacto de su llegada a Lora, pero en 1757 se encontraba ya residiendo en la calle Roda de $\mathrm{Abajo}^{32}$. En su localidad natal llevaría una existencia bastante tranquila en los años siguientes, aunque sin renunciar a participar en la vida social y religiosa. Eso es, al menos, lo que parece deducirse del apoyo económico que prestó, por ejemplo, para la construcción de la ermita de Nuestro Padre Jesús, cuyas obras finalizarían en 1764 (Fernández Martín, 1988, p. 14; Lozano Nieto, 1986, p. 102). En otro orden de cosas, al tomar el relevo a su hermano mayor, tras su fallecimiento en 1767, como apoderado de Pedro Messía de la Cerda, bailío de Lora, nuestro personaje pasó a residir en su palacio situado en la calle del mismo nombre. Allí estuvo avecindado hasta 1770, a pesar de que desde 1768 residía ya en La Carlota, con su sobrina María Manuela de Quintanilla ${ }^{33}$.

\section{b) Dignidades y nombramientos}

Como caballero profeso, Fernando de Quintanilla tenía derecho y obligación de participar en los capítulos de la Orden, poco frecuentes en el siglo XVIII y en los que se trataban asuntos eclesiásticos, civiles y militares, así como posibles reformas de los estatutos (Tiron, 1848, pp. 11-12). Sin embargo, sus ocupaciones y la distancia que era necesario recorrer para estar presente en Malta nos hacen pensar que difícilmente pudo acudir a alguno de aquellos a los que fuera convocado. Por ejemplo, para el que tuvo lugar en el último domingo de noviembre de 1776, tras recibir aviso por carta de 20 de abril anterior, optó por conferir poder especial el 17 de agosto al comendador Juan Zarzana para que lo representara, pues su empleo en las Nuevas Poblaciones y su ocupación como procurador general de las provincias de Andalucía en dicha orden

30 A.H.N., Inquisición, leg. 3602, s.f. Representación de Fernando de Quintanilla al rey, 9 de noviembre de 1771 .

31 A.H.N., Fondos Contemporáneos, Gobernación, leg. 279, exp. 6. Carta de Fernando de Quintanilla a Miguel de Múzquiz, 8 de julio de 1778.

32 A.M.L., Secretaría General, Padrones y censos, leg. 109. Padrón municipal de 1757.

33 A.M.L., Secretaría General, Padrones y censos, leg. 109. Padrón municipal de 1770. 
le impedían viajar ${ }^{34}$. Por otro lado, aunque desconocemos la fecha y circunstancias de su concesión, nos consta que fue caballero Gran Cruz, es decir fraile laico, de la Sagrada Religión de San Juan ${ }^{35}$, dándose la circunstancia de que la insignia Gran Cruz que recibió es la que luce actualmente la Virgen de Setefilla en su pecho ${ }^{36}$ por habérsela donado el propio Quintanilla en agradecimiento después de encomendarse a ella en una ocasión en la que subiendo a caballo la Escalereta que conduce a su santuario, con un niño subido delante en la montura, se le desbocó el équido sin que ocurriera ninguna desgracia (Montalbo, 1960, p. 261; González Carballo, 2012, p. 60).

Como caballero de justicia podía optar a gestionar alguna encomienda de la Orden, aunque no parece que se le tuviera en cuenta para ello hasta después de habérsele encargado las labores de subdelegado de las Nuevas Poblaciones de Andalucía. A comienzos de la década de los años setenta se le adjudicó la encomienda de Almazán, a la que renunció en 1781 para pasar a disfrutar de la de Cubillas y Cubillejas; que conservó hasta su fallecimiento en 1800. La considerable distancia que mediaba entre los lugares habituales de residencia de nuestro protagonista y las posesiones de estas encomiendas, situadas en Castilla, hizo que las gestionase mediante arrendamiento. La de Almazán la arrendó siempre a Pedro Alcaide Márquez, vecino de Campisábalos ${ }^{37}$; exceptuando los bienes localizados en Andalucía, de los que se ocupó Juan Pascual Martínez, procurador del número y audiencia de Jaén ${ }^{38}$. La encomienda de Cubillas y Cubillejas la recibió por título otorgado por el gran maestre frey Manuel de Rohan fechado en Malta a 28 de diciembre de 1781, por lo que otorgó escritura de poder el 20 de marzo de 1782 para que pudiera tomar posesión de ella y administrar sus rentas Santiago Cristóbal Tobalinas, residente en la villa de Castronuño, que era capitán retirado de caballería agregado a la plaza de la villa y corte de Madrid ${ }^{39}$. Asimismo,

34 Archivo Notarial de Posadas (en adelante A.N.PO.), La Carlota, Escribano Ignacio del Pozo, prot. 889 , año 1776 , s.f.

35 Gusseme, Andrés de, Noticias pertenecientes a la historia antigua y moderna de Lora del Río, Alcolea del Río, Setefilla y Arva, en Andalucía (1758), Lora del Río: ACAL, 1981, p. 77. Aunque Gusseme publicó su obra en 1758, en esa edición no hubo ninguna referencia a Fernando de Quintanilla. La interpolación en la que se daba cuenta de los empleos y dignidades que tuvo este individuo se debió realizar hacia 1799, lo que permitió que estuviera presente en el manuscrito, hoy perdido, que Miguel Bago Quintanilla facilitó a José García Millán y que este dio a la imprenta como Apéndice IX de su libro Apuntes sobre las fiestas celebradas en honor de la Virgen Stma. de Setefilla en el año de 1920 en su villa de Lora del Río, editado en 1934.

Esta insignia tenía un valor considerable, como lo demuestra el que fuera tasada, en 1853, en un inventario de bienes de la Hermandad de la Virgen de Setefilla con el valor de 6.000 reales.

Tenemos datos de los arrendamientos comprendidos entre 1773 y 1781 (A.N.PO., La Carlota, Escribano Ignacio del Pozo, prot. 889, año 1773, s.f.; A.N.PO., La Carlota, Escribano Juan Vázquez, prot. 886, año 1778 , ff. 1r-14r).

A.N.PO., La Carlota, Escribano Ignacio del Pozo, prot. 889, año 1774, s.f.

A.N.PO., La Carlota, Escribano Juan Vázquez, prot. 886, año 1782, ff. 27r-30v. 
correspondían también al comendador de esta última las rentas del mayorazgo de Orejones, de 1.200 reales, impuesto sobre unas casas principales en Madrid ${ }^{40}$.

En este caso, la concesión de la encomienda vino acompañada de un pleito en el Consejo de Castilla vinculado con las dos dehesas que la integraban; las cuales, aunque divididas por el río Duero, se extendían por una superficie total de 10.437 fanegas y 3 celemines en el partido de la ciudad de Toro. En el tiempo que había estado vacante tras la muerte de frey Juan Elías de Castilla, su anterior poseedor, se dictó una provisión a favor de los arrendadores de pastos y bellotas de la encomienda que redujo el importe de lo que debían pagar anualmente y que Quintanilla consideró injusta y lesiva para sus intereses. El apoderado del anterior comendador había acordado, en 1780, el arriendo por cinco años de los pastos y bellotas a varios ganaderos de la Mesta por 65.500 reales anuales, pero estos litigaron exitosamente en 1781 para reducir esa tasa. Al tener noticias de la referida provisión, nuestro personaje inició, en junio de 1783, las gestiones para que se nombrasen peritos y se volviera a evaluar la dehesa, logrando que el litigio se resolviera finalmente a su favor en julio de $1784^{41}$ (González Carballo, 2018, pp. 144-146).

Finalmente, Quintanilla también pudo disfrutar como titular, y no solo como arrendador, de los bienes más relevantes de la orden: los bailiajes. En este caso, su importancia radicó más en el estatus que conferían a sus titulares que en las rentas que pudieran obtener de ellos, pues solo la de Lora producía importantes beneficios. De los tres que existieron en el Gran Priorato de Castilla y León, llegó a disfrutar de dos, aunque no simultáneamente. En 1795 ya era titular del bailiaje de las Nueve Villas ${ }^{42}$, promocionando dos años más tarde al del Santo Sepulcro de Toro (González Carballo, 2018 , p. 143) ${ }^{43}$. Como en todo señorío, estos estuvieron integrados por tres elementos: la jurisdicción señorial sobre algunos lugares, los bienes de dominio pleno y las prestaciones y rentas sobre otros bienes. En el de las Nueve Villas, también conocido como bailía de Población de Campos, se conservaba en el siglo XVIII solo el domi-

$40 \quad$ Fernando de Quintanilla otorgó poder especial el 24 de marzo de 1784 para cobrar estas rentas desde el 1 de abril de 1783. A.N.PO., La Carlota, Escribano Juan Vázquez, prot. 886, año 1784, s.f.

$41 \quad$ A.N.PO., La Carlota, Escribano Juan Vázquez, prot. 886, año 1783, s.f.

42 Lista de los caballeros del M. Yll. Priorado de Castilla y León, [S.1.], [s.n.], 1795, p. 29. Desconocemos desde cuándo poseía este bailiaje (aunque su concesión debió ser posterior a 1791), pero parece que no estuvo mucho tiempo bajo su administración pues en 1796 aparece como titular Martín de la Plata (véase Guía del estado eclesiástico seglar y regular de España en particular y de toda la Iglesia Católica en general para el año de 1796, Madrid, Imprenta Real, 1796, p. 10) y en 1797 lo era Pedro de Ulloa y Carvajal, Guía del estado eclesiástico seglar y regular de España en particular y de toda la Iglesia Católica en general para el año de 1797, Madrid, Imprenta Real, 1797, p. 10.

43 En 1796 su titular era Juan Ignacio Ibarburu, Guía del estado eclesiástico seglar y regular de España en particular y de toda la Iglesia Católica en general para el año de 1796, Madrid, Imprenta Real, 1796, p. 10. 
nio jurisdiccional sobre tres pueblos: Población de Campos, Itero Seco y Espinosa de Villagonzalo, sobre los que el bailío ejercía la jurisdicción civil y criminal, alta y baja, mero y mixto imperio; aunque por la frecuencia en la que estaba ausente solía nombrar un gobernador que impartiese justicia en su nombre. En ellos mantenía el privilegio de entregar las varas y tomar juramento a los alcaldes y alguaciles elegidos por estas localidades, así como el de nombrar algunos empleos como el de escribano de Población de Campos o el de visitar y revisar las cuentas de los concejos de esta y Espinosa. Los bienes de dominio pleno consistían entonces en algo menos de mil hectáreas, aunque distribuidas en 855 parcelas repartidas por más de treinta pueblos que se integraban dentro de la bailía; circunstancia que reducía bastante las opciones para rentabilizar su explotación. Finalmente, las contribuciones sobre otros bienes las pagaban todos los vecinos - excepto hidalgos, clérigos, viudas y alcaldes en funciones - de los tres pueblos antes mencionados y se establecían en función de su patrimonio; a lo que había que sumar el tributo de ocho cargas y siete cuartos de pan que debía entregar el concejo de Espinosa y los 4.000 maravedíes y 24 gallinas que pagaba Itero. Por último, también ejercía el bailío de las Nueve Villas la jurisdicción espiritual, en nombre del gran prior, sobre cuatro prioratos: Arbejal, Camesa, Santiurde y San Juan de Riacedo (Revuelta González, 1971, pp. 215-221 y 226-229).

Por lo que respecta a la bailía del Santo Sepulcro de Toro, creada por la Orden del Hospital de San Juan de Jerusalén con posesiones heredadas de los sepulcristas tras su supresión por el papa Inocencio VIII en 1489, estaba compuesta por el núcleo de la ciudad torensana con su iglesia y monasterio del Santo Sepulcro de Toro, donde la extinta Orden del Santo Sepulcro celebraba sus Capítulos Generales, así como por otras dos parroquias en esta ciudad: la de San Juan de los Gascos y la de Santa Marina, actualmente desaparecidas; a las que se sumaban otras iglesias como la de San Cristóbal de Fuentespreadas, Villalar ${ }^{44}$ y la de Santa María de Ribera-Torre Duero. Entre las prerrogativas del bailío figuraban los nombramientos de priores de los ya mencionados templos del Sepulcro, de San Juan y de Santa Marina de Toro, del Sepulcro de Zamora y de San Cristóbal de Fuestespreadas; y el de capellán de la capilla de la Ribera. En estos dos últimos lugares, además, ostentaba la jurisdicción civil y criminal con la elección de alcaldes, justicia y escribano. En el caso de la iglesia del Santo Sepulcro de Zamora, extramuros de la ciudad, solo se poseía el edificio, no correspondiendo al bailiaje ni jurisdicción, ni bienes, ni rentas, tierras, diezmos o similares. Por último, también formaba parte de ella la iglesia de la Veracruz de Segovia.

$44 \quad$ El bailiaje de Toro tuvo en Villalar una ermita dedicada a Santa Eugenia y un molino localizado sobre el río Ornija. La situación extramuros del templo facilitó que decayese su uso litúrgico, quedando arruinada a finales del siglo XVII. Del mismo modo, tampoco hay referencia a que se conservase después de este siglo el molino del Ornija, por lo que es probable que en la época en que Fernando de Quintanilla actuó como bailío solo quedasen ruinas. 
A pesar de que cada priorato incluido en el bailiaje tenía sus propios recursos que permitían su subsistencia, el bailiaje también tenía otras heredades, fueros y rentas repartidos por distintas localidades próximas a Toro, entre los que destacaban los 5.000 maravedíes que poseía sobre las alcabalas de las carnicerías y ganados de Toro. Igualmente, también disponía de una casa para su bailío, situada junto al monasterio del Santo Sepulcro de Toro, pero independiente de este, compuesta por dos plantas y desde la que se llevaban las labores de gestión del bailiaje. No obstante, durante la Modernidad los bienes de este bailiaje irían perdiendo valor, a lo que se sumó la falta de constancia en las obligaciones que habían contraído algunas familias nobiliarias que obtuvieron el patronato de algunos de los templos que lo integraban, por lo que su deterioro se aceleró. Eran muchas las posesiones que conllevaban unos elevados gastos y, por tanto, los beneficios que quedaban finalmente al bailío eran escasos (Pérez Monzón, 1999, pp. 196-197 y 204; Pérez Monzón, 2002, p. 160; Villaseñor Sebastián, 2011, pp. 56-57; Rincón García, 2015, p. 866).

\section{Incremento de ingresos y patrimonio: la rentabilidad de promocionar en la Religión de San Juan}

Aunque Fernando de Quintanilla se situaba, en sus últimos años de vida, entre los vecinos más influyentes y acaudalados de Lora del Río, consideramos que ello nunca habría sido posible sin los enormes beneficios que le reportó su estrecha vinculación con la orden de San Juan, intensificados más aún si cabe después de 1776. Su herencia familiar y su salario le habrían permitido una vida acomodada, pero muy lejos de lo que realmente pudo disfrutar. Como uno de los hijos más pequeños entre la numerosa descendencia de Juan Rodrigo de Quintanilla Andrade y Sotomayor, tenía pocas opciones de disfrutar de una gran herencia. Desconocemos a cuánto ascendió, pero no debió de ser mucho si tenemos en cuenta que el mayorazgo paterno hizo recaer la mayor parte de los bienes en su hermano mayor Antonio de Quintanilla, regidor de Lora y Carmona y alcalde mayor perpetuo de esta última ciudad, mientras que su hermano Bartolomé de Quintanilla, el segundón, heredó el mayorazgo de sus abuelos maternos (González Carballo, 2018, pp. 119-122). Además, aunque los Quintanilla formasen parte de las oligarquías locales de Lora y de Carmona, no disponían de grandes fortunas, como lo prueba el hecho de que Juan Rodrigo de Quintanilla solo poseyera en la primera de estas localidades, en 1749, diez yuntas, quince cahíces de sementera, dos manadas de ovejas, un hato de vacas, 120 aranzadas de olivar, un molino de aceite, un molino de pan, cuatro huertas y una heredad de viñas (Castellano Cuesta, 2018, p. 50) ${ }^{45}$.

$45 \quad$ Esta información se corresponde con las averiguaciones catastrales realizadas en Lora para cumplir con lo dispuesto por el marqués de la Ensenada en virtud del real decreto de 10 de octubre de 1749. 
En febrero de 1771 Fernando de Quintanilla carecía de cualquier tipo de bien inmueble o propiedad rústica en su localidad natal, siendo propietario solo de una modesta ganadería valorada en 10.511 reales $^{46}$; no obstante, también tenía arrendado y labraba entonces el cortijo de Azanaque, del que no nos consta los beneficios que le reportaba, pero nos pone en la pista de la relevancia que pudieron tener esos bienes arrendados en el conjunto de sus ingresos anuales ${ }^{47}$. En este sentido, todo apunta a que el arrendamiento del bailiaje de Lora, como veremos, tuvo una importancia capital para acceder, a coste reducido, a importantes cantidades de tierra para roturarlas y dar cabida a esa ganadería.

En lo que concierne a salarios, sabemos que trabajó durante los primeros años en las colonias de Andalucía sin recibir ninguna retribución. Por ello, Olavide solicitó para él en agosto de 1771 alguna asignación, ya que había abandonado sus labores para ir a La Carlota. En una afirmación no exenta de las exageraciones vinculadas a cualquier solicitud que implicase pedir dinero, el superintendente nos dice que su subdelegado no «tiene con qué vivir, pues ha gastado en estos años cuanto pudo recoger de sus ocupaciones anteriores, y abandonó estas por entregarse todo a este servicio» (Perdices de Blas, 1988, 3, p. 1344). El rey consideró excesiva la cantidad sugerida, señalándole solo 30.000 reales anuales en mayo del año 1772, los cuales mantuvo hasta septiembre de 1784, momento en el que logró su ansiada jubilación con 15.000 reales al año (Hamer Flores, 2009, pp. 202-203).

Mejor fortuna tuvo, en cambio, gracias a su vinculación a Religión de San Juan. En primer lugar, como arrendador del bailiaje de $\operatorname{Lora}^{48} \mathrm{y}$, más tarde, como poseedor de encomiendas e incluso de algunos de los bailiajes más importantes de la Lengua de Castilla y León. Tanto es así que nuestro personaje llegó a ser uno de los miembros más influyentes de la Orden en esa demarcación. Lamentablemente, como ya sostenía Pedro García Martín (1999, p. 254), aún no se ha estudiado con profundidad el patrimonio sanjuanista, especialmente para los siglos de la Modernidad, por lo que el

46 Esta ganadería estaba compuesta por 84 bueyes, 4 toros, 90 vacas, 30 novillos y novillas, 31 becerros y becerras, 9 yeguas, 8 caballos capones, 4 potros, 1 mulo, 29 asnos, 134 cerdos y 140 lechones. A.M.L., Hacienda, leg. 546. La desaparición, en la última Guerra Civil española, de los protocolos notariales del partido judicial de Lora del Río nos impide poder estudiar hoy todos aquellos instrumentos públicos que, sin duda, nuestro personaje otorgó en esta localidad.

48 Aunque la información que tenemos es muy escasa, nos consta que también actuó como apoderado, al menos, en otra encomienda: la de Alcolea. Lo facilitó el hecho de que esta estuviera junto al bailiaje de Lora, del que se había desgajado a comienzos del siglo Xvi (González Carballo, 2004, pp. 125-139). La residencia en Malta de su titular, frey Juan de Vargas y Villalobos, hizo posible que nuestro personaje fuese su apoderado entre 1789 y 1793 (González Carballo, 2018, p. 146). Las rentas anuales de esta encomienda, aunque considerablemente inferiores a las de la bailía de Lora, fueron muy importantes, tanto que a mediados del siglo XIX suponían para su titular unos ingresos de 42.242 reales al año (Castellano Cuesta, 2018, p. 83). 
investigador se encuentra ante la dificultad de enfrentarse a numerosas lagunas que impiden ir más allá de un planteamiento general. Esta limitación, en cualquier caso, consideramos que no nos ha impedido un acercamiento lo suficientemente detallado como para poder alcanzar conclusiones válidas.

El arriendo del bailiaje de Lora estuvo muy vinculado a la familia Quintanilla en la segunda mitad del siglo XVIII, tanto es así que cuando Antonio de Quintanilla falleció en 1767, su hermano Fernando continuó con esa práctica (González Carba1lo, 2018, p. 121). Al tratarse del más rico, sus rentas eran tan considerables ${ }^{49}$ que el arrendamiento se realizaba con la condición de entregar a su titular 150.000 reales anuales y de pagar 42.255 reales de responsiones cada año al tesoro de la $\operatorname{Orden}^{50}$, quedando el resto de los beneficios a favor del arrendatario. Unos ingresos a los que hay que sumar el poder que implicaba representar al bailío y cómo este podía orientarse a beneficiar a los más allegados.

Sabemos que, ya desde 1767, nuestro personaje generó numerosas tensiones en la localidad al patrocinar, con permiso del bailío ${ }^{51}$, diversos repartimientos de tierras de propios, tan abundantes en Lora que se cuantificaban por encima de las siete mil fanegas. Repartos en los que, según manifestó el propio concejo loreño, benefició a sus familiares cercanos, especialmente a su sobrina María Manuela de Quintanilla y Arze, que permaneció soltera y vivió siempre muy próxima a él desde que quedara huérfana de padre. El síndico se mostró especialmente contundente al afirmar que «la discordia, pleitos y enemistades que hay en el vecindario desde el año de setecientos sesenta y siete es originado de haber don Fernando de Quintanilla, como apoderado del señor bailío, sin facultad real, dado todos los terrenos útiles y palmares, abrevaderos y veredas a los vecinos que le pareció»». Todos estaban convencidos de que esas donaciones eran un modo encubierto de acceder Quintanilla a ellas ya que ambos

49 Carecemos de información acerca de los beneficios que reportaba la bailía de Lora a su titular en la época que analizamos, pero, de modo orientativo y teniendo en cuenta que todo apunta a que se produjo una reducción en los beneficios, en los años centrales del siglo XIX rentaba a su titular 187.744 reales anuales (Castellano Cuesta, 2018, p. 83).

50 En el arriendo por tres años que se firmó en 1775, prorrogado dos años más a su finalización, y en la renovación firmada, mancomunadamente con su hermano Luis de Quintanilla en 1780, por otros dos años se fijó la condición de abonar al bailío de Lora, Pedro Messía de la Cerda, un total de 150.000 reales anuales, más otros 41.255 reales en concepto de responsiones a la orden. Este arriendo tuvo una prórroga de dos años, tras los cuales nuestro personaje volvió a solicitar, mancomunadamente con su sobrino Joaquín María de Briones y Quintanilla, el arriendo con la mejora de 10.000 reales sobre los 150.000 de contratos anteriores (A.N.PO., La Carlota, Escribano Ignacio del Pozo, prot. 889, año 1774, s.f.; González Carballo, 2018, p. 132).

$51 \quad$ Al ser tierras novales, es decir, puestas en cultivo por vez primera, los diezmos no correspondían a la Iglesia sino al bailío; por tanto, no debe extrañarnos que este avalara las acciones de Quintanilla, aunque hubiera fundadas sospechas de que los procedimientos seguidos hacían nulos los repartimientos por no contemplar la intervención de quienes tenían la competencia de autorizarlos. 
gestionaban sus bienes mancomunadamente; algo facilitado, dicho sea de paso, por su estancia en La Carlota, que obligaba a María Manuela a actuar como su apoderada.

La primera de esas concesiones la realizó en 1774, al adjudicarle 500 fanegas de tierra lindantes con el monte de Pelabarbas; que se completaron con otras 360 fanegas baldías situadas en ese mismo monte no mucho después. Consciente de la provisionalidad de estos repartos, María Manuela de Quintanilla decidió solicitar en 1776 al Consejo de Castilla la concesión perpetua de las referidas 360 fanegas a cambio de un canon anual de 2.000 reales y la obligación de costear su desmonte y cultivo, así como la construcción de una capilla y oratorio. Una iniciativa que generó un profundo rechazo en un sector de las oligarquías loreñas, que se disputaban la hegemonía en el sector ganadero y que temían que el poder de los Quintanilla y los suyos se incrementase merced a la puesta en cultivo de esas tierras. Temores que parece que no eran del todo infundados, pues María Manuela de Quintanilla era considerada, en 1777, como una de las labradoras más ricas de la localidad, ya que cultivaba hasta 2.000 fanegas de tierra con 75 arados, tenía 300 vacas, 40 yeguas, 2500 cabezas de ganado lanar, 800 cabras y 800 cerdos; siendo además propietaria de 50 aranzadas de olivar en Carmona y de 20 aranzadas de estacas de olivar en tierras baldías de Lora.

Recibida la petición, el Consejo de Castilla dispuso que se midiera y tasara el terreno solicitado, procediéndose a ello en agosto de 1777 , de lo que resultó que su superficie era sensiblemente inferior a lo indicado pues solo alcanzaba las 270 fanegas, que se valoraron en 85.329 reales. Aplicando el cálculo del 3\% habitual en los censos y arrendamientos, resultó un canon anual de 2.560 reales; no obstante, los peritos consideraron que era más adecuado rebajarla hasta los 1.280 reales. En vista del peritaje, el concejo de Lora procedió a informar sobre este particular, mostrando un consenso casi total en oponerse a la solicitud; tan solo el personero manifestó su conformidad, aunque con la salvedad de que le parecía insuficiente el canon anual fijado por los peritos y expresando, además, la necesidad de que se repartiesen entre los vecinos del pueblo las más de siete mil fanegas de tierras de propios. Los regidores y sobre todo el síndico expusieron varios argumentos para rechazar la petición. En primer lugar, defendieron que de tener que hacerse el reparto este no debía recaer en una persona tan manifiestamente acaudalada, sino en yunteros y pelantrines de la localidad; mientras que, en segundo lugar, expusieron su argumento más sólido: cualquier repartimiento realizado sin la aprobación del concejo de Lora era nulo. Aunque Fernando III el Santo concedió en el siglo XIII la jurisdicción loreña a la Orden Hierosolimitana, en agosto de 1477 esta concedió a su concejo todas las tierras baldías de la jurisdicción; de ahí que el bailío no pudiera disponer de ellas unilateralmente como estaba sucediendo, ya que sin la aprobación del ayuntamiento esos repartos solo podían ser calificados como usurpaciones. 
La complejidad del asunto en el tema de la solicitud realizada por María Manuela, pues el Consejo de Castilla pidió al ayuntamiento un segundo informe en 1778, hizo que las costas del proceso alcanzasen cifras tan significativas que la solicitante llegó a proponer en ese mismo año que estaba dispuesta a renunciar a su petición a cambio de que se le concediese la dehesa baja del Marchante, una de las de propios, cerrada y acotada sin aprovechamiento comunal. Lamentablemente, desconocemos si esta oferta encontró algún eco, ya que las gestiones quedaron interrumpidas hasta 1782, fecha en la que un nuevo repartimiento realizado por Fernando de Quintanilla impulsó otra queja del concejo de Lora ante el Consejo de Castilla. En la primavera de ese año nuestro personaje repartió unas 1.000 fanegas de tierras baldías, con el objetivo fundamental de que los beneficiarios las pusieran de plantío. No solo volvía a desafiar al concejo, sino que incluso le causaba una considerable merma en sus ingresos, pues se dejarían de percibir los arriendos por bellota y otros conceptos de esas tierras sin ninguna contrapartida al estar exentas de tributar hasta que esos plantíos estuvieran en producción.

En esta ocasión, seguramente influenciado por el apoyo que en las nuevas colonias le manifestaban sus vecinos al ser beneficiarios de lotes de tierra, Quintanilla actuó con más astucia que en ocasiones anteriores al incrementar los repartos de parcelas de cuatro y ocho fanegas, con los que se ganó el favor de un considerable sector de la población local, y haciendo algo menos llamativas las concesiones a sus familiares y adeptos. El monte de Pelabarbas, tras el frustrado intento que acabamos de analizar, fue nuevamente elegido para su distribución en lotes a varios vecinos; entre los que destacaron los realizados a dos sobrinas suyas: Catalina Montalvo y Quintanilla recibió 100 fanegas, mientras que a María Manuela de Quintanilla se le adjudicaron 154 fanegas

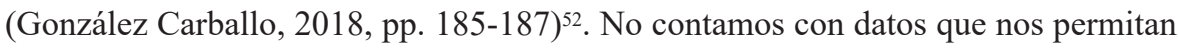
saber si las quejas de las autoridades municipales surtieron algún efecto, pero sí nos consta que en diciembre de 1785 estas denunciaban movimientos para impedir que continuasen los recursos que se tramitaban en el Consejo «sobre usurpación de tierras concejiles $\rangle^{53}$. Se acusaba directamente al gobernador o alcalde mayor nombrado por el bailío, que pudo aprovechar la debilidad en la que se encontró el concejo desde 1777 hasta 1787, cuando el Consejo de Castilla mandó secuestrar ocho de los nueve cargos de regidor, que serían reemplazados por nombramientos realizados a propuesta del corregidor de Carmona. El referido gobernador aprovechaba, al parecer, para ofrecer reparos en aquellas propuestas que podían suponer un problema para los intereses del

A.H.N., Consejos, leg. 31421, exp. 1.

A.M.L., Gobierno, leg. 17, libro 2 (Actas Capitulares de la villa de Lora, 1782-1786). Sesión de 1 de diciembre de 1785 . 
bailío que, como ya hemos tenido ocasión de manifestar, resultaba muy beneficiado con los repartimientos por el aumento de los diezmos novales ${ }^{54}$.

Ahora bien, junto a los beneficios, tanto legales como irregulares, del arrendamiento de la bailía de Lora, también hemos de considerar las rentas que Quintanilla obtuvo de las encomiendas y bailiajes que ya hemos visto que tuvo en la Orden. La encomienda de Almazán, que debió recibir en algún momento entre 1770 y $1773^{55}$, le produjo unos ingresos de 18.500 reales anuales hasta 1778 y de 19.000 reales anuales hasta $1781^{56}$; sin incluir lo que pudieran rentar las tres propiedades de esta encomienda en Andalucía, que nuestro personaje gestionaba aparte ${ }^{57}$. La presencia hospitalaria en Almazán se remonta, al menos, a 1200; año en el que la Orden poseía allí una iglesia dotada de derechos parroquiales: San Juan de Acre, actualmente desaparecida. Unos bienes que se incrementaron durante la Baja Edad Media hasta poseer a mediados del siglo XIV una iglesia, una casa, heredamientos, aceñas y viñas en esa villa que le proporcionaban una renta de 1.500 maravedíes (Barquero Goñi, 2012, pp. 181-182).

Estos ingresos de Quintanilla aumentaron significativamente cuando el gran maestre de la Orden decidió en 1781 que, en lugar de la de Almazán, pasase a disfrutar de la encomienda de Cubillas y Cubillejas. Sus rentas anuales se valoraban por entonces en una media de 69.433 reales, además de los diezmos y portazgos, que todo apunta a que se mantuvieron en los sucesivos arriendos mientras Quintanilla la poseyó

$54 \quad$ A.M.L., Gobierno, leg. 18, libro 1 (Actas Capitulares de la villa de Lora, 1787-1790). Sesión de 25 de mayo de 1787.

55 Dado que no disponemos del título de concesión, consideramos que esta debió de producirse en algún momento entre 1770 y 1773 por dos motivos: de un lado, porque en febrero de 1770 no se hace referencia a esta circunstancia en el padrón de vecinos de Lora (A.M.L., Secretaría General, Padrones y censos, leg. 109) y, de otro, por las peticiones realizadas por Quintanilla en 1774 y 1775 a su arrendatario de que tomara posesión judicial o extrajudicialmente de varias posesiones de la encomienda que estaban ocupadas por particulares, una demostración de propiedad difícilmente comprensible en caso de no haberla recibido poco tiempo antes (A.N.PO., La Carlota, Escribano Ignacio del Pozo, prot. 889, años 1774 y 1775, s.f.).

56 Estas son las cantidades acordadas con Pedro Alcaide Márquez, vecino de Campisábalos, para los periodos comprendidos desde el 1 de mayo de 1773 hasta el 30 de abril de 1778 (A.N.PO., La Carlota, Escribano Ignacio del Pozo, prot. 889, año 1773, s.f.) y desde el 1 de mayo de 1778 hasta el 30 de abril de 1783 (A.N.PO., La Carlota, Escribano Juan Vázquez, prot. 886, año 1778, ff. 1r-14r.). Es probable que los bienes de esta encomienda se deteriorasen, o que incluso alguno se enajenara, pues a mediados del siglo xix las rentas anuales que generaba eran solo de 18.774 reales, cifra inferior a los 19.000 reales de los últimos arrendamientos que Quintanilla hizo de los bienes situados en Castilla, que se incrementarían con los localizados en Andalucía (Castellano Cuesta, 2018, p. 83).

57 Estas propiedades en Andalucía eran un cortijo y tierras que llamaban de San Juan (en el término de Úbeda, en Jaén), otras 300 cuerdas de tierra en el sitio de la Golosilla (cerca de la Higuera de Andújar) y una porción de tierra en el sitio de la vega de Andújar, junto al camino que bajaba al Marmolejo. La gestión de todos estos bienes se la confirió Quintanilla a Juan Pascual Martínez, procurador del número y audiencia de Jaén, en junio de 1774 (A.N.PO., La Carlota, Escribano Ignacio del Pozo, prot. 889 , año 1774 , s.f.). 
(González Carballo, 2018, pp. 144-146). Una prueba evidente de que esta concesión implicaba un mejor posicionamiento dentro de la orden de San Juan nos la ofrece el dato de lo que aportaba cada una de esas encomiendas a sus arcas en 1795, pues mientras que la de Almazán, en manos entonces de Fernando de Cárdenas, apenas contribuía con 3.341 reales de responsiones, la de Cubillas y Cubillejas tributaba con 10.035 reales $^{58}$. A comienzos del siglo XVI, de la antigua villa y castillo de Cubillas solo quedaba la casa-palacio en la que habitaban el comendador y las personas a su servicio, por lo que se convirtió en un coto redondo. Sus riquezas procedían del monte de Cubillas y de las aceñas que existían en el río Duero desde época medieval, junto a algunos bienes de poco valor en los cercanos lugares de Villalar, Marzales, Villabelli, Pobladuras, Pozo Antiguo, Abezames, Bustillo, Madrid, Tiedra y Casasola. El comendador, además, tenía la jurisdicción espiritual y temporal alta, baja, mero mixto imperio, con horca y cuchillo, el nombramiento de las principales autoridades del lugar, al igual que percibía los diezmos mayores y menores de los bienes producidos en esta encomienda (Pérez Monzón, 1999, p. 114).

No es extraño, pues, que todavía a mediados del siglo XIX se considerase al coto de Cubillas como «una de las mejores posesiones de Castilla» (Madoz, 1984, p. 290). Por aquel entonces ya no formaba parte de los bienes de la Orden, pues su alto valor hizo que estuviera entre las primeras propiedades enajenadas cuando el rey español pasó a ser el Gran Maestre, cerrándose su venta el 17 de octubre de 1807 a favor de Pedro Ceballos, caballero de la gran cruz de la Orden de Carlos III (Pérez Monzón, 1999, p. 114).

Por si todo esto no hubiera sido suficiente, no mucho más tarde también recibiría nuestro personaje sucesivamente dos bailiajes y sus rentas asociadas. Circunstancia nada baladí teniendo en cuenta que el Gran Priorato de Castilla y León solo poseía tres bailiajes, y Fernando de Quintanilla pasó de la tercera a la segunda de ellas con más rentas mientras seguía administrando la más importante de todas al residir dentro de su jurisdicción (Tirón, 1848, p. 40). Aunque no sabemos la fecha exacta de concesión del bailiaje de las Nueve Villas, en 1795 nuestro personaje ya aparece al frente de ella ${ }^{59}$. Su importancia fue más cualitativa que cuantitativa, pues apenas aportaba 2.675 reales como responsiones anuales a la Orden. Además, no parece que Quintanilla la gestionase durante mucho tiempo, pues en 1796 ya tenía un nuevo bailío al frente. Ahora bien, la fortuna le acompañó de nuevo muy pronto, pues en 1797 fue confirmado como bailío del Santo Sepulcro de Toro, que sí poseería hasta su fallecimiento en enero del

$58 \quad$ Lista de los caballeros del M. Yll. Priorado de Castilla y León, [S.1.], [s.n.], 1795, p. 30.

$59 \quad$ El acceso a este bailiaje debió tener lugar después de 1791, cuando lo poseía Martín Nicolás de la Plata, Lista de los caballeros de justicia, capellanes conventuales de justicia y frey-sirvientes de armas, recibidos en el M.Y. Priorado de Castilla y León, Malta, Imprenta Magistral, 1791, p. 26. 
año 1800 (Montalbo, 1960, p. 365; González Carballo, 2018, p. 143). Al igual que el bailiaje anterior, tampoco en este caso las rentas fueron muy elevadas, como lo prueban los 3.739 reales y 30 maravedíes que debía aportar anualmente al Tesoro de la Orden $^{60}$. En ambos casos, la existencia de edificios religiosos y personal eclesiástico consumía buena parte de los beneficios, por no mencionar las conquistas que habían ido consiguiendo, con el paso de los años, los concejos que las integraban para reducir las contribuciones a las que estaban obligados (Pérez Monzón, 1999, p. 23). Aun así, esto no restaba valor al considerable estatus que confería el ser bailío en la Orden.

Todas estas fuentes de ingresos facilitaron la conformación de un importante patrimonio — constara o no a su nombre - y, a la par, le permitieron manifestar con claridad ante sus convecinos su elevada posición social. Quizá una de las mejores pruebas de ello la encontremos en el donativo y préstamo patriótico voluntario que se solicitó a los españoles a través de la real cédula de 19 de junio de 1798, pues en su nombre y en el de su sobrina María Manuela donó el 17 de julio un total de 3.000 reales. Una cifra muy por encima de las más elevadas que se recaudaron en Lora del Río, pues ningún otro donativo individual superó los 1.000 reales ${ }^{61}$. Además, no podemos olvidar que también ocupó desde 1778 hasta su muerte, que tuvo lugar en enero de 1800, al igual que hicieran su padre y hermano durante décadas, el cargo de mayordomo de la Hermandad de la Virgen de Setefilla, patrona de Lora del Río (Lozano Nieto, 1986, p. 130).

\section{Conclusiones}

Una vez plasmados en los apartados anteriores los contenidos que nos proponíamos analizar en el presente trabajo, consideramos que es el momento de ofrecer al lector las conclusiones más destacadas. Nuestro objetivo principal era el de realizar una aproximación a las ventajas y beneficios que reportó a frey Fernando de Quintanilla, primer subdelegado de las Nuevas Poblaciones de Andalucía entre 1768 y 1784, su pertenencia como caballero profeso a la Orden Militar y Hospitalaria de San Juan de Jerusalén. En este sentido, hemos podido comprobar que con anterioridad a su llegada a las nuevas colonias su presencia en la Orden, bien a través de cargos o bien mediante la administración de alguno de sus bienes, era muy limitada. Lo único realmente significativo fue su ocupación como arrendador del bailiaje de Lora a partir de 1767, coincidiendo con el fallecimiento de su hermano mayor, el cual venía arrendándolo anteriormente. Un empleo que le garantizó importantes ingresos, pues no en vano se

Lista de los caballeros del M. Yll. Priorado de Castilla y León, [S.1.], [s.n.], 1795, p. 29.

A.M.L., Secretaría General, leg. 49. 
trataba de la posesión con mayores rentas de toda la Lengua de Castilla y León, y que además parece que le permitió beneficiar a familiares y a sí mismo, usando como testaferro a su sobrina, gracias a sucesivos repartimientos de tierras baldías.

No obstante, el verdadero detonante para que reactivase su cursus honorum dentro de la Orden parece que estuvo en la detención y posterior proceso inquisitorial del superintendente Pablo de Olavide. En los años que trabajó bajo su autoridad experimentó una profunda transformación personal, asumiendo muchas de las ideas ilustradas de aquel; pero debió renunciar a todo ello por simple estrategia de supervivencia, pues la condena a Olavide era suficiente argumento como para hacer borrón de toda esa etapa. Tal fue su voluntad por dejar atrás las nuevas colonias que solicitó al gobierno durante años, aunque sin éxito hasta 1784, poder dejar su destino en ellas para retirarse a su localidad natal. Unos años en los que claramente aprovechó para mejorar su posición y, a la vez, sus ingresos. La concesión, en 1772, del grado de intendente de provincia como premio a su buen hacer en las Nuevas Poblaciones de Andalucía, parece que fue el impulso definitivo para seguir aspirando a nuevos cargos y dignidades que en 1768 no parecían tener mucho interés para él.

Primero llegaron las encomiendas, la de Almazán hacia 1773 y, tras renunciar a ella, la de Cubillas y Cubillejas en 1781. Un cambio que le permitió triplicar los ingresos anuales que había recibido hasta este último año por la primera que se le adjudicó. Pero su promoción no quedó ahí, pues fue el beneficiario de dos de los tres bailiajes del Gran Priorato de Castilla y León, ciertamente más importantes por el estatus que concedían a sus titulares que por las rentas que generaban. En 1795 Fernando de Quintanilla actuaba como bailío de las Nueve Villas o Población de Campos, recibiendo dos años más tarde el bailiaje del Santo Sepulcro de Toro. Si a ello sumamos que, simultáneamente, actuaba también como administrador del bailío de Lora, resulta innegable el destacadísimo papel que tuvo nuestro personaje en la Orden en sus últimos años como entidad independiente, pues Napoleón Bonaparte invadió y se anexionó la isla de Malta en junio de 1798, obligando a la Orden a abandonarla, y en 1802 el rey Carlos IV incorporó a la Corona las Lenguas y Asambleas de España, quedando constituido como gran maestre de la Orden en nuestro país (Revuelta González, 1971, p. 231). 


\section{Bibliografía}

Aguayo Pérez, Simón \& Hamer Flores, Adolfo (2007), «Un ilustrado sevillano. Don Fernando de Quintanilla, intendente de las Nuevas Poblaciones de Andalucía», en Fílter Rodríguez, J.A. (coord.), Ilustración, ilustrados y colonización en la campiña sevillana en el siglo XVIII, Sevilla, ASCIL, pp. 271-282.

ANTón RAmírez, Braulio (1865), Diccionario de bibliografía agronómica y de toda clase de escritos relacionados con la agricultura; seguido de un índice de autores y traductores con algunos apuntes biográficos, Madrid, Imprenta y Esterotipia de M. Rivadeneyra. < https://doi.org/10.5962/bhl.title.32767>

BArquero GoÑI, Carlos (2012), «Los Hospitalarios en la Extremadura castellana (siglos XII-XIII)», en García Fitz, F. y Jiménez Alcázar, J.F. (coords.), La historia peninsular en los espacios de frontera: las 'Extremaduras' históricas y la 'Transierra'(siglos XI-XV), Murcia, Sociedad Española de Estudios Medievales y Editum, pp. 179-187.

CALderón España, María Consolación (1993), La Real Sociedad Económica Sevillana de Amigos del Pais: su proyección educativa (1775-1900), Sevilla, Universidad de Sevilla.

Caro Baroja, Julio (1952), «Las nuevas poblaciones de Sierra Morena y Andalucía. Un experimento sociológico en tiempos de Carlos III», Clavileño, 18, pp. 52-64.

Castellano Cuesta, Teresa (2018), El ilustre loreño D. Fernando de Quintanilla y Andrade (1719-1800). De la villa de Lora a las Nuevas Poblaciones de la baja Andalucía, Sevilla, Ediciones Almijar.

Defourneaux, Marcelin (1965), Pablo de Olavide, el afrancesado. México, Editorial Renacimiento. Traducción al español del original francés: Pablo de Olavide ou l'Afrancesado. Paris, Presses Universitaires de France, 1959.

Fernández Martín, María Mercedes (1988), Arquitectura civil del siglo XVIII en Lora del Río, Lora del Río, A.C.A.L.

García Martín, Pedro (1999), «El patrimonio de la Lengua de Castilla y León de la Orden de Malta o todo lo que adquiera el religioso es para su religión», Hispania Sacra, vol. 59/1, no 230, pp. 251-168. <https://doi.org/10.3989/hispania.1999.v59. i201.624>

García Millán, José (1934), Apuntes sobre las fiestas celebradas en honor de la Virgen Stma. de Setefilla en el año de 1920 en su villa de Lora del Río, Murcia, Editorial La Verdad.

González Carballo, José (2004), «La división de la Cámara Prioral de Lora y su separación del Priorato. La creación de la encomienda de Alcolea y el bailiaje de Lora», Espacio y Tiempo. Revista de Ciencias Humanas, 18, pp. 125-139. 
González Carballo, José (2012), «La casa del bailío frey don Fernando de Quintanilla», en Setefilla. XXV Aniversario Proclamación del Patronato Litúrgico y Coronación Canónica de María Santísima de Setefilla, 1897-2012, Lora del Río, Hermandad Mayor de Nuestra Señora María Santísima de Setefilla, pp. 55-69.

González Carballo, José (2018), La familia Quintanilla. Lora y Carmona, siglos $X V$-XX. Genealogía y estudio histórico. Sevilla, Espacio y Tiempo de Lora.

Hamer Flores, Adolfo (2007), «Traicionando el espíritu del Fuero. Las tierras solicitadas por el intendente Fernando de Quintanilla en La Carlota (1781-1785)», Al-masan, 3, pp. 15-29.

Hamer Flores, Adolfo (2009), La Intendencia de las Nuevas Poblaciones de Sierra Morena y Andalucía, 1784-1835. Gobierno y administración de un territorio foral a fines de la Edad Moderna, Córdoba, Universidad de Córdoba.

Llopis, Enrique \& Sebastián, José Antonio (2019), «Aclarando tintes demasiado oscuros. La economía española en el siglo XVIII», Cuadernos Dieciochistas, 20, pp. 13-67. <http://dx.doi.org/10.14201/cuadieci2019201367>

Lozano Nieto, Juan Manuel (1986), Un pueblo andaluz y su Virgen. Historia de Lora y Setefilla, Barcelona, Editorial Claret.

Montalbo, Nicolás (1960), Resumen histórico de Ntra. Sra. María Santísima de Setefilla, patrona de la villa de Lora del Río, Sevilla, Artes Gráficas Salesianas.

Perdices de Blas, Luis (1988), La agricultura en la segunda mitad del siglo XVIII en la obra y empresa colonizadora de Pablo Olavide Jauregui, Madrid, Editorial Complutense, 3 vols.

Perdices de Blas, Luis (1992), Pablo de Olavide (1725-1803), el ilustrado, Madrid, Editorial Complutense.

PÉREz Monzón, Olga (1999), Arte sanjuanista en Castilla y León. Las encomiendas de la Guareña y su entorno geo-histórico, Valladolid, Junta de Castilla y León.

PÉrez Monzón, Olga (2002), «Documentos para el estudio del arte de las Órdenes de San Juan y del Santo Sepulcro», Stvdia Zamorensia, 6, pp. 159-207.

Revuelta González, Manuel (1971), «La bailía de Población de la orden de San Juan de Jerusalén», Publicaciones de la Institución Tello Téllez de Meneses, 12, pp. 203-237.

Rincón García, Wifredo (2015), «Patrimonio artístico de la Orden de San Juan de Jerusalén en España: una aproximación y algunos ejemplos», en Alvarado Planas, J. y De Salazar Acha, J. (coords.), La Orden de Malta en España (1113-2013), Madrid, Editorial Sanz y Torres, pp. 859-928.

RODRÍGUEZ ENNES, Luis (2018), «Anotaciones en torno a la represión de la mendicidad y la vagancia en la España del Antiguo Régimen y su sustitución por medidas de 
seguridad», Revista de Estudios Histórico-Jurídicos, 40, pp. 267-279. < https:// doi.org/10.4067/S0716-54552018000100267>

Salazar y Acha, Jaime de (2015), «La Orden de San Juan de Malta en España y sus protagonistas: los caballeros», en Alvarado Planas, J. y De Salazar Acha, J. (coords.), La Orden de Malta en España (1113-2013), Madrid, Editorial Sanz y Torres, pp. 229-254.

TIRON, René (1848), Historia y trajes de las órdenes religiosas militares, Barcelona, Agencia Médica Catalana.

Villaseñor Sebastián, Fernando (2011), «La iglesia del Santo Sepulcro de Zamora: aproximación histórico-artística», Anástasis, 3, pp. 23-36.

\section{Fuentes impresas}

Censo de Floridablanca 1787. Comunidades Autónomas Meridionales, Madrid, INE. Editado en 1987.

Continuación de las memorias de la Real Sociedad Patriótica. $N^{\circ} 2$, Sevilla, Impresores de la Real Sociedad, 1779.

Estatutos de la Real Sociedad Patriótica de la M.N. y M.L. ciudad de Sevilla y su reinado, Sevilla, Imprenta de don Manuel Nicolás Vázquez y compañía, 1778. Ejemplar conservado en la Biblioteca Nacional de España con la signatura $\mathrm{VE} / 392 / 25$.

Guía del estado eclesiástico seglar y regular de España en particular y de toda la Iglesia Católica en general para el año de 1796, Madrid, Imprenta Real, 1796.

Guía del estado eclesiástico seglar y regular de España en particular y de toda la Iglesia Católica en general para el año de 1797, Madrid, Imprenta Real, 1797.

Gusseme, Andrés de, Noticias pertenecientes a la historia antigua y moderna de Lora del Río, Alcolea del Río, Setefilla y Arva, en Andalucía (1758), Lora del Río, ACAL, 1981.

Lista de los caballeros de justicia, capellanes conventuales de justicia y frey-sirvientes de armas, recibidos en el M.Y. Priorado de Castilla y León, Malta, Imprenta Magistral, 1791. Ejemplar conservado en la Biblioteca de la Universidad de Navarra con signatura FA.Foll 006.387

Lista de los caballeros del M. Yll. Priorado de Castilla y León, [S.1.], [s.n.], 1795. Ejemplar conservado en la Biblioteca Foral de Vizcaya con la signatura RF-124.

Madoz, Pascual (1984), Diccionario geográfico-estadístico-histórico de Castilla y León. Valladolid. Valladolid, Junta de Castilla y León. Edición facsímil del original publicado entre 1845 y 1850. 
Memorias de la Sociedad Económica. Tomo tercero, Madrid, Por don Antonio de Sancha, 1787.

Mercurio Histórico y Político que contiene el estado presente de la Europa, lo sucedido en todas las cortes, los intereses de los príncipes y generalmente todo lo más curioso, perteneciente al mes de julio de 1772, Madrid, Imprenta Real de la Gazeta, 1772.

Señores socios de la Real Sociedad Patriótica de la ciudad y reino de Sevilla, existentes en el año de mil setecientos ochenta y cinco, [Sevilla, 1785. Ejemplar conservado en la Biblioteca Nacional de España con la signatura R/41604(5)]. 
